\title{
La vida orillera: agitaciones violentas y arremetidas del mar en el Pacífico colombiano
}

Shore life: violent upheavals and sea lunges in the Colombian Pacific Ocean

RESUMEN

A orillas del océano Pacífico colombiano la vida sucede en un escenario conmocionado por las agitaciones del agua y de la tierra. En el litoral, la fuerza del mar suscita una inestabilidad constitutiva de sus mundos en tanto las vidas orilleras luchan, obstinadas, con dicha alteración. Colapso y creación trabajan como latencias que hacen pesada y aprietan la vida, pero que no impiden su florecimiento. Desde el encuentro etnográfico entendido como una relación vital que se cría en conversación con otros, esta reflexión se acerca a La Barra, población costera de Buenaventura. Seguimos las huellas de un devenir abrazado a la marea y a las dificultades que imponen otras fuerzas violentas. Esto es dado, dicen los barreños refiriéndose a su playa, pero es también arrebatado ya que no sólo el mar se lo lleva todo.

Palabras clave: arremetidas del mar, Pacífico colombiano, destrucción creadora, vida orillera.

\section{Abstract}

On the shores of the Colombian Pacific Ocean, life intermingles with the sea, in a place shaken by the restlessness of water and land. On the coast,
MARIA ISABEL

Galindo OrRego

ICESI, Cali, Colombia.

\ mariaisabelgalindo47@gmail.com

(D) ORCID: 0000-0002-8440-9131

$\checkmark$ Google Scholar 
the force of the sea creates an instability that is constitutive of the community that live there. These coastal lives fight stubbornly with such restlessness and instability. Collapse and creation concur, amidst destructive latencies that "hacen pesada y aprietan la vida" (make life heavy and squeeze it), but do not prevent life from flourishing. The point of departure of this essay is the ethnographic encounter as a vital relation that is nourished in conversation with others. This paper seeks to approach La Barra, a coastal community close to Buenaventura, in whose experience, we can trace social processes intertwined with the tide and the difficulties created by other violent forces. "Esto es dado" (this is given), say the people from La Barra, when they talk about their beach, but this is also taken from them: not only the sea takes it all.

Keywords: ocean's restlessness, Pacific Ocean, creative destruction, orillera life.

[...] escucha atentamente la voz de nuestros ríos; escucha a los temibles árboles de la gran selva; el canto endemoniado, blanquísimo del mar; escúchalos, padre mío, Serpiente Dios. ¡Estamos vivos; todavía somos! Del movimiento de los ríos y las piedras, de la danza de árboles y montañas, de su movimiento, bebemos sangre poderosa, cada vez más fuerte. (Katatay, José María Arguedas)

Como los pantanos de manglares de la costa Pacífica: vida agudizada, muerte agudizada, juntas [...] de la muerte que pasa a la vida seguida de la vida que pasa a la muerte de la que proviene.

(Mi Museo de la Cocaína, Michael Taussig)

\section{Barreras del mar y vidas orilleras}

C agitan los cimientos. El mar cincela el mundo (moviéndolo, devorándolo, creándolo) y da forma a los contornos de la tierra. Con su furia avanza sobre las costas hechas de viento, agua, barro, madera y arena. Se recoge y avanza. Llega. Siempre llega: bravura que trabaja para amansar y producir la vida orillera. El corte muestra al mar, es su huella. Es el punto en el que en marea alta descansa y hasta allí cova la arena. Para los barreños es la pista que les habla de qué tan cerca está el agua de las casas que tejen y siembran a la vera del océano. Cuando llega muy cerca, algunos desbaratan para construir de nuevo, otros entregan al mar los restos de su vida inundada y empiezan de nuevo. El trabajo del mar 
cría y destruye las playas en que mundos costeros habitan y dan perpetuamente vuelta: el mar trae vuelta lo que se lleva, la arena de la playa está viva y se mueve movida por el mar que la lleva a otras playas y que vuelta da vuelta1.

La Barra es un pueblo costero asentado a orillas del mar en el Pacífico vallecaucano, en Buenaventura, al suroccidente de Colombia. Está ubicado muy cerca del lugar en que el caudaloso río San Juan descarga sus aguas al océano, trazando el límite entre los departamentos del Valle del Cauca y el Chocó. Hoy viven allí más o menos 100 familias, organizadas desde 2002 en torno a un consejo comunitario de comunidades negras que ocupa un territorio titulado colectivamente en julio de 2015. Diversos orígenes poblaron La Barra. Hombres y mujeres provenientes de abajo, nacidos en ríos y playas chocoanas al norte de La Barra; malagueños llegados del espacio en que se abre la selva para que entre el mar en la Bahía de Málaga, al oriente de La Barra; caminantes del Naya, del Yurumanguí o de la costa nariñense, más arriba, al sur de La Barra, vinieron a buscar la vida en esta playa y han dado forma a la franja litoral en la que hace poco más de 70 años enterraron sus primeros ranchos ${ }^{2}$.

La vida, sembrada en las orillas, al borde del mar, ríos, esteros y ciénagas, fecunda formas de ser orilleras. Habitar orillas fluviales y mareñas no es exclusivo de la gente de La Barra; otras geografías dibujan también esa existencia liminar que transcurre entre el agua y la tierra firme, como lo pensó Orlando Fals Borda (1979) para los pueblos anfibios de las llanuras aluviales del Magdalena. En el Atrato, por ejemplo, las comunidades se dicen orilleras y su vida depende de esa íntima relación con el río. Según un testimonio recogido en esa región del Pacífico chocoano, "el río nos prestó sus orillas para que viviéramos en ellas" (Cagüeñas et al., 2020, p. 183). Las márgenes litorales en que habitan los barreños se conciben en oposición al mundo del interior y del centro del país. En el caso de La Barra, vivir en las orillas es también experimentar la incertidumbre que nace de las bruscas transformaciones, la inestabilidad, la costumbre de

\footnotetext{
En cursiva aparecerán categorías de uso local. En algunos casos su sentido se articulará al cuerpo del texto, en otros se aclarará en notas al pie. El corte es la marca que el mar deja en la máxima marea, es una señal que puede leerse en la arena e indica qué tanto subirá el agua. En las montañas del suroccidente colombiano, el corte es "el lugar específico donde quedó el trabajo, y en general todos los lugares donde se trabaja" (Anzola, 2017, p. 59). En ambos casos tiene que ver con el cultivo y la formación del mundo: una crianza tan creadora como destructiva. Covar es hacer hueco en la tierra. El mar cova la arena como la pala el suelo en que se siembra. Vuelta es una expresión que indica "de nuevo", algo que retorna cíclicamente; señala también remoción, como cuando se da vuelta a la tierra para que lo que está encima quede abajo, se pudra y fertilice lo que está por crecer.

Las referencias de "arriba" y "abajo" apuntan a una relación espacial mediada por los flujos de vientos y corrientes. El norte es "abajo" porque hacia allá empujan dichas fuerzas cuando se navega; lo contrario sucede al viajar hacia el sur, "arriba".
} 
lanzarse al mar. Es caminar al borde, en las fronteras en que la vida y el desastre se tocan.

La presente reflexión es parte de una propuesta de investigación que se ha ido perfilando los últimos dos años en el marco del doctorado en antropología de la Universidad del Cauca, en Popayán, Colombia. Los compromisos y fascinaciones que en esta intención puedan leerse son producto de la amistad estrecha que desde hace varios años sostengo con los habitantes de La Barra. La aproximación etnográfica que da forma a las inquietudes e intuiciones que aquí se esbozan está inspirada en las últimas visitas que hice a La Barra en julio y diciembre de 2019; sin embargo, desde 2008 he estado cerca de este mundo costero. Mis búsquedas e interlocuciones con los barreños han sido recogidas en reflexiones anteriores que alimentan parte de la presente indagación (ver Galindo, 2019 y Galindo, en prensa).

He querido acompañar las vidas que se agitan, se asientan y se diluyen suscitadas por el agua. He buscado acercarme a la manera en que La Barra (sus habitantes humanos, el perfil de sus costas acantiladas, la grafía que dibujan sus enredados esteros al abrirse paso por los fangosos manglares en los que se esconden las pianguas, su arena viva y juguetona encendida de cangrejos, su mar celoso y caprichoso, las casas y árboles y fracasos y deseos que tropelean en su playa con la marea, los restos de viejas barras y el impulso de otras nuevas) experimenta la alteración de su mundo hecho de agua y se obstina en habitarlo en medio de latencias destructivas que hacen pesada y aprietan la vida, pero que empujan su florecimiento. El derrumbamiento de un mundo que, sin embargo, se levanta tercamente frente al océano no es sólo telúrico. La polución, la escasez y la guerra aparecen en las vidas que con "maña y capricho", al decir de Luis Alberto Suárez, las enfrentan. El capricho y la maña, intuye Suárez (en prensa), son expresiones de una vida que quiere vivir en tanto se somete al mundo a la vez que se expone a él y lo transforma, trabajándolo. La historia de la vida es la historia del trabajo que ha hecho posible esa vida. Es una historia de lucha.

Épocas de abundancia en el litoral son recordadas con nostalgia, mientras los orilleros siguen llevando una vida que ahora pesa y se enferma más que antes. Los peces y camarones proliferaban en un tiempo en que las embarcaciones del pueblo tenían que amanecer en los pescaderos (lugares de buena pesca) porque los animales empezaban a jalar desde bien temprano. Luego la abundancia menguó y ahora los peces son más visajosos: se han corrido, espantados por los grandes barcos camaroneros que succionan el océano. Esto es dado, dicen los barreños refiriéndose al 
lugar en que habitan y que el agua puja por recuperar. Parece ser que es también violentamente arrebatado: no sólo el mar se lo lleva todo. Viejas y nuevas destrucciones suscitadas por conmociones telúricas y sociales muestran que en La Barra el mundo colapsa constantemente en tanto se abre camino en medio de los escombros que el mar, el capital y la guerra dejan.

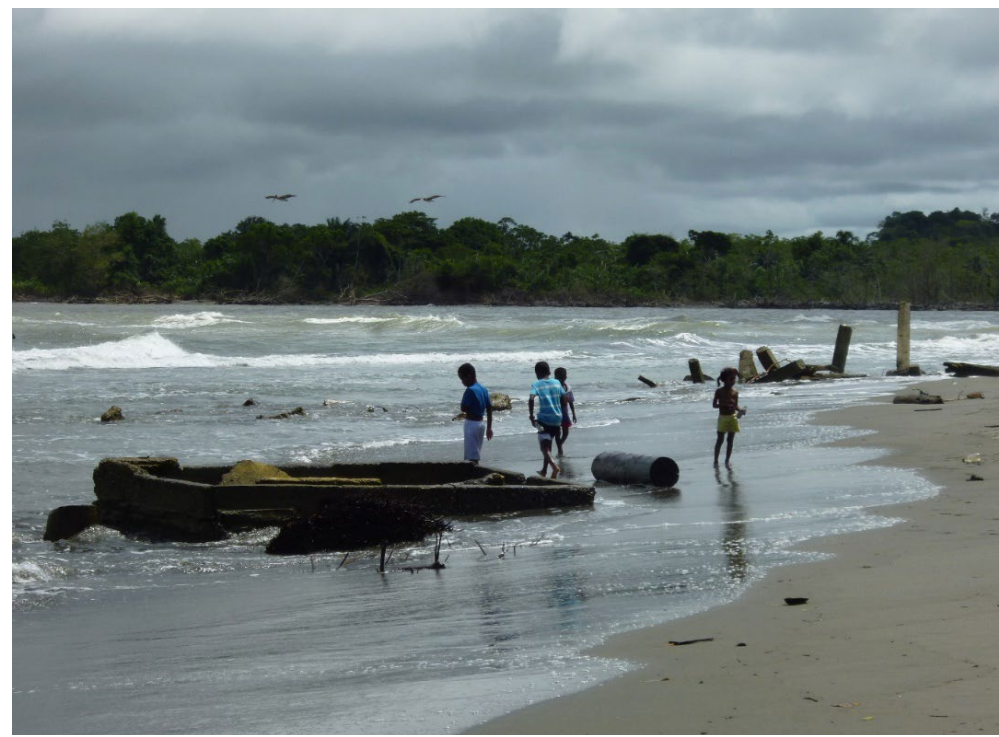

Imagen 1. La Barra, julio de 2016.

Fuente: archivo personal de la autora.

\section{El mundo que se cría y se destruye}

La Barra mira al mar y ve de frente al sol ponerse. Detrás suyo se despliega la selva como un espeso abismo por el que amanece y de cuyas profundidades también nace la noche. La línea costera está hecha de arena y de acantilados oscuros que separan el mar de la tierra firme en que se levanta una loma a la que no llega la marea y que ha servido de suelo para el nuevo pueblo. Almendros, altísimas palmas, guamos, pomarrosos y árboles de pan crecen en la playa. Casas de madera pintada de colores refulgentes desleídos por la sal y por el tiempo - por el viento- que sopla violento desde el océano se abren camino por las cambiantes formas del pueblo. Retumban sus techos cuando el viento que agita el mar se deja sentir con la fuerza del sueste, que es el tiempo más imponente. Las embarcaciones no salen y aquellas que lo hace pasan trabajo. El viento impulsa la marea, emputa (embravece) las olas y acentúa las corrientes. Es pesado estar en el mar cuando se arrebata porque el temporal, la tempolina, quiere arrancar lo que yace en la tierra y puede hacer naufragar lo que navega en la marea. 
En estas orillas del Pacífico colombiano, el mundo adopta la forma que las mareas, los vientos, las corrientes marinas, la fuerza de los ríos, quebradas y esteros esculpen y erosionan. En esta playa forjada y desgastada por un mar abierto e impetuoso, al ritmo de pujas y quiebras se suceden las semanas, mientras las altas y bajas mareas pautan el paso de los días. Las pujas son mareas fuertes, que bajan y suben mucho, impulsadas por la luna llena y la luna nueva; las quiebras son más sosegadas y tienen lugar en el cuarto menguante y el cuarto creciente de la luna. Dos veces al mes puja la marea y otras dos veces el agua quiebra, intercalándose cada semana. Dos veces al día el mar roza su punto más alto sobre la playa, los acantilados o el cauce de ríos y esteros, y dos veces al día baja a su mínimo nivel. Al subir, el agua llena; al bajar mengua. En puja, se llama cabeza de agua al cambio de marea que luego de pujar subiendo cada día quiebra, merma; esto ocurre dos veces al mes.

Este compás acuático moldea el espacio y el tiempo: algunos lugares se inundan y se secan dependiendo de la marea y las horas se marcan atendiendo a la cercanía del océano. Las lanchas pescadoras esperan el agua para zarpar mar afuera y las piangüeras responden a los momentos en que el manglar seca, en la vaciante, cuando baja la marea, para poder arrimar sus embarcaciones y caminar entre el raicero que se extiende sobre el barro, todavía de agua pero ya cerca de la selva. Hay lugares por los que no puede transitarse en determinada marea: algunos esteros secan con la vaciante y la playa se cierra cuando el agua llega. El mundo se transforma con el flujo y el reflujo de la marea. El mar cubre las costas y el horizonte de agua abraza el suelo, el cielo y el océano. El mar se retira y su estela húmeda dibuja una inmensa extensión de arena mojada que en el día el sol quema y caminan personas y trabajan cangrejos.

Los barreños conocen muy bien esta cadencia y, en conversación con ella, sortean su vida. Sin embargo, desde hace un par de años, la transformación habitual del espacio devino destrucción y el caserío empezó a difuminarse en el océano. Las pujas de 2014 se han comido el pueblo $\mathrm{y}$, desde entonces, sus habitantes no cesan de tropeliar con la marea. La historia de La Barra está hecha de conmociones propias del mundo litoral. La mutación del espacio por efecto de fuertes mareas y sacudidas terrestres es uno de los rasgos particulares de la región (Arocha, 1999; Galindo, 2019; Giraldo, 2009; Leal, 2000; Oslender, 2008; Pedrosa, 1996; West, 1957). Singulares formas de estar en el mundo conversan con transformaciones abruptas de la tierra: marejadas, estremecimientos tectónicos y crecientes dan forma a una suerte de agencia telúrica que interviene en el destino de pueblos que habitan la línea costera. 


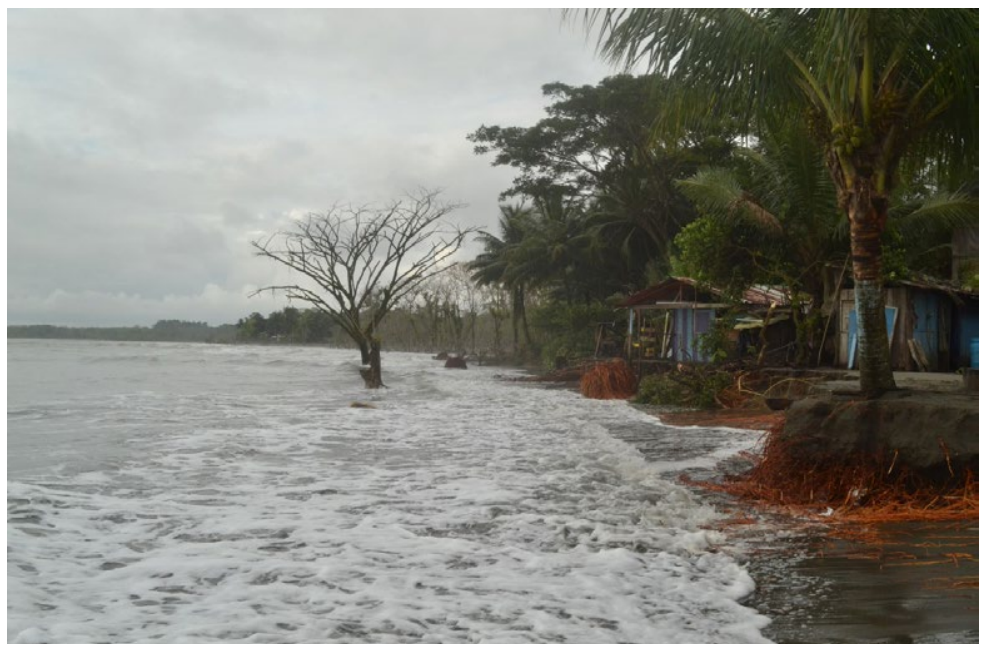

Imagen 2. La Barra, diciembre de 2018.

Fuente: archivo personal de la autora.

Tales conmociones, en el Pacífico colombiano, se cruzan con las tramas oscuras del conflicto armado, las economías extractivas, las avanzadas del desarrollo y el narcotráfico urdidas con intensidad desde finales de la década de 1990. No sólo el mar ha hecho temblar aquel laberinto mareño y fluvial alguna vez figurado como un "recóndito litoral", imagen en que destellan los confines fronterizos y olvidados de la nación. Arremetidas del mar y agitaciones de la guerra se han dejado sentir bruscamente en la región. Más allá de La Barra, la conjugación de dichas fuerzas puede rastrearse en otros pueblos orilleros, igualmente convulsionados. Alfredo Vanín, venido de los ríos profundos de la selva pacífica timbiqueña, recuerda la historia palpitante del Pacífico nariñense al ritmo de una "trashumancia obligada":

En San Juan [Nariño], la historia de las fundaciones se ha diluido. Muy pocos recuerdan de dónde provienen o cómo se fundó la playa que ahora queda sepultada bajo las olas como resultado del pasado maremoto de 1979 [...] La playa primigenia siguió erosionándose a lo largo de los años, perdiendo cada vez mayor extensión con cada puja grande. (Vanín, 2017, pp. 96-97)

Al tiempo, la violencia asociada al conflicto armado y al tráfico de drogas revelaba un escenario desolador, escribía el mismo Vanín sobre los primeros años de los 2000: "pueblos desplazados, ecosistemas arrasados, culturas amordazadas y mutiladas, unidades productivas deshechas, territorios usurpados" (2017, p. 43). A propósito del despojo, el desplazamiento y los asesinatos de los que han sido objeto las poblaciones del Pacífico 
colombiano desde la última década del siglo pasado, Jaime Arocha (2004) y Arturo Escobar (2004) argumentan que el litoral ha experimentado una nueva faceta de desterritorialización en la que la abrupta modificación de sus paisajes biofísicos y culturales resulta evidente.

Según un relato recogido por Alfredo Molano, Cabo Manglares -en el extremo occidental de Colombia- también en el Pacífico sur, "estaba mal ubicado y un día la mar lo combatió y el río no lo defendió [...] Entre las dos aguas lo fueron atacando, socavaron sus playas y [...] el mar y el río fueron criando otro" (Molano, 2017, p. 49). Cuenta, para los mismos inicios de siglo, que:

por las aguas de los ríos Satinga, Sanquianga, Patía bajan cadáveres día y noche [...] Van por debajo del agua, como van los submarinos llenos de coca construidos en esos manglares, a "preñar" barcos en altamar [...] Desde 2001 ["Chaín el Mago", su interlocutor], ha dado cristiana sepultura a cuerpos no identificados en el cementerio de Bocas de Satinga, que como el pueblo mismo, está amenazado con que las aguas lo desaparezcan con todo y sus desaparecidos. (Molano, 2017, pp. 62-65)

Los parajes atrateños, en el Pacífico chocoano, vivieron también en esa época la mixtura de guerra y embates de la naturaleza. Natalia Quiceno cuenta cómo en los primeros años de este siglo "las inundaciones del río habían aumentado por el recrudecimiento de la guerra en la región. Los cuerpos y las muertes recibidos por el río, a causa de una violencia casi cotidiana, eran también narrados y vividos por la naturaleza" (Quiceno, 2016, p. 174). Acerca de la misma región, Daniel Ruiz-Serna explica que "el 2002 fue un año particularmente difícil en el Bajo Atrato [...] un periodo de terror caracterizado por los asesinatos selectivos de los líderes de los consejos comunitarios" (Ruiz-Serna, 2020, pp. 24-25). Según esta aproximación, la "mala muerte" de decenas de combatientes paramilitares que defendían con sus armas la avanzada del monocultivo de palma aceitera ha dejado huellas en aquel mundo fluvial de cuyas orillas emergen presencias terribles como consecuencia de la violencia sentida también por la selva.

En un periodo histórico en el que el modo de producción hegemónico en su fase neoliberal, brutalmente extractivista, es cuestionado por su responsabilidad en la destrucción del planeta, la conjugación de cataclismos telúricos -acuáticos y tectónicos- con los efectos del capital y de la guerra invita a pensar en el colapso de mundos arrasados tanto por el impulso de fuerzas geológicas y atmosféricas como por las inclemencias de las desigualdades socioeconómicas y de la violencia armada 
que las resguarda. Al reflexionar acerca de la manera en que algunos proyectos económicos succionan el Pacífico sur colombiano mediante la tala maderera, las plantaciones palmeras, la extracción de oro y de platino y la industria camaronera, rompiendo los tejidos de la vida local, Jaime Arocha (1991) afirma que "estos colapsos [económicos, atravesados por auges y decadencias] son tan impredecibles y desestabilizadores como un temblor de tierra" (p. 106). Explica, además, que "si mares, mareas y maremotos tornan vacías ciertas ideas de porvenir, más lo pueden lograr aquellas conmociones dependientes de la naturaleza de los productos de la región" (Arocha, 1991, p. 112).

En La Barra, no sólo el mar amenaza con arrancar las casas y revolverlas en el océano con todo lo que existe: el pescado también escasea, la carnada se corre o yace muerta sobre la arena. La guerra se siente y el mundo se envenena. La vida está dura, apretada, pesada. Y los barreños la llevan, la cargan, la arrastran en el vaivén constante que es su mundo inestable por el acuático impulso que lo provoca y por los ímpetus violentos que cada tanto anclan en sus playas. Casimiro, pescador hasta antes de que el mar lo asustara con una tempolina que encegueció su lancha en la densa bruma del mar abierto y dedicado ahora a los paseos ecológicos ofrecidos en temporadas altas de turismo, se duele al ver cientos de peces muertos sobre la playa. En julio de 2019, hileras de sardinas encallaban en la arena y la pudriciña (el olor putrefacto) derramada por el viento amenazaba con espantar a los turistas. Él insistía en la presencia de venenos que le echan al agua para hacer minería en los ríos que salen al mar, además de la dinamita que usan para profundizar el canal marítimo de Buenaventura con explosivos que alarman a los animales, y envenenan.

\section{Colapso, ruinas y petrificación del mundo}

El mundo estalló en 2001. Viejas y nuevas odiseas inundaron los abismos del mar y del espacio. En el Pacífico colombiano, la masacre del Naya, río que serpentea entre el Valle y el Cauca antes de arrojarse al mar, en 2001, inauguraría un tiempo de terror. Comandada por el Bloque Calima de las Autodefensas Unidas de Colombia, la avanzada paramilitar irrumpió en la vida pacífica: más de 3000 desplazados resultaron de esta misión sobre la que Éver Veloza García, alias 'HH', confesaría años después. El propósito de dicha incursión paramilitar, según los testimonios de quienes la llevaron a cabo, "era crear el Bloque Pacífico, que delinquiría desde las costas de Nariño hasta las de Chocó, para apoderarse de las finanzas que dejaba el cobro de gramaje a los narcotraficantes que sacaban drogas por ese corredor" (Verdad abierta, 19 junio de 2012). 
Hace poco menos de diez años, en 2012, Jonathan, "Raspacoco", uno de mis amigos más cercanos de La Barra y con quien compartí en esa época palabras, viajes y viches, me contó que la vida se había puesto pesada desde que las Torres Gemelas (ubicadas en otro mundo, en un lugar muy lejos y muy alto) se desplomaron. La pesca desde entonces empezó a escasear y la bonanza de camarones que en otros tiempos habían experimentado fue diezmándose estrepitosamente. Siempre me intrigó eso que, en apariencia, resultaba ser una absurda causalidad. Luego pensé que aquella era la forma en que algunos pueblos arrinconados violentamente, como productores de materia prima en la también violenta división internacional del trabajo, asumían su relación con el mundo. Se trataba de una explicación que los barreños articulaban al sentirse empujados vertiginosamente hacia el ocaso de las buenas épocas de pesca en un escenario global en el que la depredación de sus mares dificultaba la vida. La apertura del litoral anunciada por Belisario Betancur en 1985, escribía Alfredo Vanín en 1991, "mostró al país y al mundo el promisorio mar del año 2000 [...y] dio paso a una nueva penetración: le había llegado al Pacífico la hora de integrarse al desarrollo mundial" (Vanín, 2017, pp. 79-80). El mar del nuevo milenio fue entonces promesa de desolaciones.

En el tiempo de antes, recuerdan algunos pescadores veteranos, más viejos que "Raspacoco", los animales abundaban y las faenas de pesca no daban descanso ni para desayunar. Había que amanecer en los pescaderos, rocas en que se encuentran los pescados que son roqueros (como el pargo), porque ellos arrimaban de mañanita y les gustaba jalar bien temprano. La abundancia menguó y los peces se volvieron visajosos: ahora son más aviones que uno, dice Casimiro, padre de Jonathan, hoy dedicado al turismo y quien se dolía por la mortandad de sardinas en 2019. En La Barra, los pescadores podían vivir de su propia pesca, una actividad vital que enfrentaba -hombre a hombre, dicen los barreños- con los animales. El pescador, guiado por las aves cuya presencia indica el lugar en que están las sardinas que seducirán luego al pescado, conversaba con esas otras agencias en cuyo encuentro se sostiene la vida. Hoy, después de la caída de las Torres en 2001, no lo olvidemos, la vida está dura y los grandes y extranjeros barcos camaroneros arrasan con todo porque el ojo de las mallas no respeta el tamaño de los animales: no se entienden, como sí el pescador de nylon y anzuelo, con esos iguales seres a cuya existencia de debe en parte la propia vida: pertenencia no enajenada en que dialogan humanos y no humanos mientras se crean y transforman mutuamente, diría Marx en sus manifiestos de 1844.

El absoluto extrañamiento respecto de su actividad vital quizás ilumine lo que antes se presentaba como un absurdo. El trabajo creador, 
entendido como práctica transformadora, y la economía local que éste sustentaba se perdían lejos, difuminándose más allá del océano en el derrumbe de un mundo ajeno cuya conmoción se sentía propia. La explosión mediática que la reprodujo hasta el cansancio (a principios del siglo XXI llegaba, también, la energía eléctrica a La Barra) fecundó la ilusión de reconocerse en ella, justo allí donde la propia vida se desconocía, se extrañaba y se elevaba hacia aquellas altas y lejanas y ajenas y gemelas torres. El trabajo enajenado, separado del trabajador tanto como éste se separa del producto de su trabajo, rompe el vínculo que amarra al ser humano con la naturaleza. Esta escisión moderna, semilla y fruto de la propiedad privada, diluye lo que Marx ([1844] 1985,143) concibió como la pertenencia del ser humano al medio natural: una totalidad en que la naturaleza se contiene a sí misma y en la que la historia humana se funde con la historia natural. Se trata de una ligazón que zurce la vida: un proceso ininterrumpido en el que el ser humano es en tanto amasa la misma materia de que está hecho.

Justo en la época en que se desplomaron las Torres Gemelas en la "capital del mundo" -y no olvidemos que es también el tiempo en que el horror fondea en el Pacífico (¿qué terrible odisea entrañará ese 2001?)- empezaron a difundirse con fuerza algunas discusiones sobre el calentamiento global. A inicios del presente siglo toma impulso la preocupación por el cambio climático y se expanden inquietudes acerca del Antropoceno. Dipesh Chakrabarty (2009) afirma que en la década de los 2000 "los signos de la crisis [...] se convirtieron en algo política y económicamente ineludible", promoviendo el debate en torno a "la huella ecológica de la población humana" (p. 52).

Investida como una nueva fuerza geológica, la historia humana se funde con la historia natural en un escenario catastrófico y convulsionado. La historiografía, por lo menos desde la apuesta de Fernand Braudel en su Mediterráneo, dirá Chakrabarty, ya reivindicaba el entorno como un elemento que moldea fundamentalmente las acciones humanas, pero la certeza de cómo el lento trabajo de la naturaleza parece acelerarse con la inmediatez del súbito comportamiento humano no aparecerá sino hasta la emergencia de las nuevas miradas sobre el Antropoceno en los albores de la década de los 2000.

En los últimos años se ha debatido la idea de que la huella geológica sea genéricamente "humana". "Capitaloceno" y "Plantacioceno" (Haraway, 2015), entre otros, son algunos de los nombres que han querido explorar en la génesis de la destrucción sin generalizar dichas causas a "lo humano". No parece fortuito que la ruptura experimentada por los barreños, 
manifestada a través de la escasez de lo que antes proliferaba, caminara de la mano del calentamiento global. No puede pensarse el cambio climático por fuera de la historia del capitalismo. Las sociedades más vulnerables ante las amenazas del transgredido mundo natural podrían ser aquellas que no pisan tan duro sobre la superficie terráquea, aquellas que no clavan tan cruelmente sus garras en las entrañas de la tierra. Los mares suben, entre otras cosas, porque el mundo se calienta, entre otras cosas, porque una parte de la humanidad arremete, succionándolos como recursos, contra los elementos que a su vez se vuelven contra quienes la mayoría de las veces no pertenecen a esa parte de la humanidad.

La guerra, la avanzada del mar sobre las costas de la tierra, la fiebre del narcotráfico, la minería mecanizada del oro y el ocaso de una época dorada en la que camarones y peces abundaban, recordada con nostalgia a lo largo del litoral, son huellas que hablan de una terrible continuidad respecto de los cuerpos, geografías y formas de hacer la vida que resultan sacrificadas en la expansión del mundo moderno-colonial. El sueño del progreso, y su correlato desarrollista contemporáneo, ha desplegado sobre las costas del Pacífico colombiano fantasías coloniales, nacionalistas y neoliberales que figuran la región como una tierra baldía, agreste, violenta y biodiversa, profusa en riqueza étnica y ecológica (Escobar, 1996). Las selvas, ríos y mares que dibujan estos bordes litorales han sentido con fuerza la extravagante tensión de ser catapultados a un futuro al que nunca se llega. $O$ de ser la sangre que alimenta un porvenir siempre esquivo, cuya estela parece ser el paisaje desolado en el que se acumulan los escombros de ajenos desarrollos, riquezas que arruinan, progresos que envenenan.

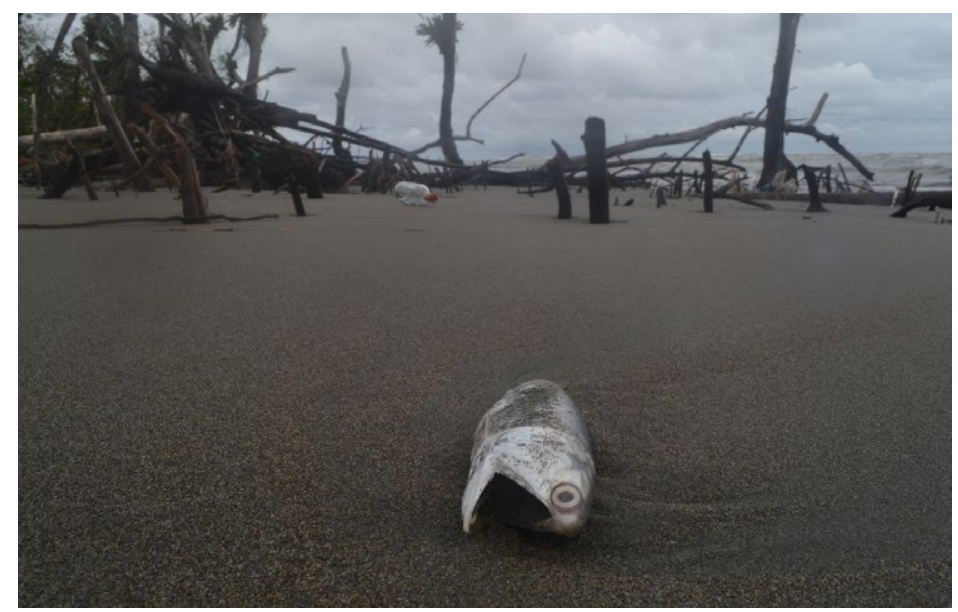

Imagen 3. La Barra, julio de 2019.

Fuente: archivo personal de la autora. 
En La Barra, los peces se volvieron visajosos y se corrieron, y los camarones menguaron alienados de aquellos que solían pescarlos. Explica el "saber experto" que el calentamiento global causa el ascenso de los mares, además de impulsar la migración de peces hacia otras profundidades dejando en vilo el sostenimiento de las economías pesqueras locales (Leyva, 2013). Lejos de los álgidos debates académicos y políticos en que se dirimen las decisiones sobre el periodo geológico en que estamos y se definen responsabilidades respecto de la destrucción del planeta, los barreños articulan formas de asumir el brutal colapso del mundo local mediante explicaciones propias que dan sentido a rupturas que de otra manera resultarían incomprensibles. El cemento que ancló en sus playas hace más o menos 30 años resulta ser otro veneno parecido, tal vez, al que ayuda a buscar oro en la minería hecha sobre los ríos que salen al mar. El azogue (mercurio) que contiene el material atrae violentamente el agua hacia las costas: al enterrar cemento en la arena molestaron al mar, al que no le gusta su presencia.

El cemento que llegó de lejos con el propósito de construir hoteles en Juanchaco y Ladrilleros, referencias turísticas de la región, instaló la promesa de convertir el litoral vallecaucano en un "balneario del Pacífico" 3 . El mismo cemento con que se proyectan carreteras que pretenden conquistar la maraña selvática para facilitar el tránsito de turistas; el mismo que sirvió para reemplazar con tanques de concreto la rusticidad de los pozos sépticos en La Barra. Ese cemento, según cuentan los barreños, se come la arena (Galindo, 2019). El cemento -"columna vertebral de la modernidad"- fue también objeto de reflexión para Michael Taussig en Mi museo de la cocaína. Como signo de lo "moderno" y de lo "bueno", este material sustituye la flexibilidad de la madera, que es más resistente ante los frecuentes terremotos de la costa sur del Pacífico colombiano. En Guapi, según encontró Taussig (2013), la iglesia, la prisión y el banco fueron los primeros edificios de concreto (p. 177).

Taussig articula la relación estrecha que hay entre cemento y cocaína, indispensable aquél para la fabricación de ésta. El derroche gestado por la producción y tráfico de drogas alimenta sueños de velocidad y de concreto: "no habría motores de 200 caballos sin la cocaína y la cocaína es la que permite que el cemento se levante en las calles

A finales de los años 60 del siglo pasado se impulsó desde la gobernación del Valle una ley que proyectaba el Pacífico vallecaucano como epicentro turístico de la región. Dicho proyecto implicaba una titulación privada de la tierra que estimuló la compra de terrenos aledaños a La Barra con fines recreativos; esta forma de propiedad ha gestado disputas respecto de la tenencia de lotes "privados" en el lugar en el que los habitantes locales han empezado a construir el nuevo pueblo, que hace parte del territorio colectivo titulado en 2015 
de los pueblos como castillos de sueños" (Taussig, 2013, p. 182). Mezclas mágicas de cemento, cocaína y velocidad inundan los horizontes fluviales del litoral y estremecen la vida de los ribereños. El cemento y la guerra asociada al narcotráfico que surca en lanchas veloces esteros y mares parecen sepultar el mundo de madera y de lento manglar que precede a la agitación moderna y que, en La Barra, devora la playa y enfurece al océano.

Las márgenes litorales en cuyas orillas se asienta la vida barreña son fronteras salobres de las que mucho han bebido proyectos centrales. Ímpetus coloniales y sueños republicanos; quimeras del progreso y esquivos desarrollos; dorados de todos los colores, nuevas y viejas conquistas de una tierra indómita y deseada. Rita Segato (2013) anuncia, con una cortante lucidez, el carácter permanentemente colonial del Estado multicultural que opera en el mundo globalizado mediante un pacto con el capital, insistiendo en el sueño del desarrollo que promete la inserción de las márgenes en el mercado global a pesar de los "reveses que la historia de nuestras naciones ya le ha propinado a esta ilusión desarrollista" (p. 19).

Gastón Gordillo (2014) persigue, en el norte de Argentina, el camino de una constelación de escombros en que logra leer los rastros de viejas y nuevas violencias ejercidas por distintos actores: conquistadores españoles e indígenas insurrectos; misioneros que quisieron seducir las almas de indios y mestizos; exploradores y militares republicanos que soñaron con amansar el "desierto"; agentes de un progreso que viajaba en rieles de tren cubiertos por la maleza y en barcos de vapor encallados en el monte; grandes finqueros dueños de tierras ganaderas; buldóceres que operan la destrucción de un espacio cuya forma se adapta brutalmente a las necesidades de la versión contemporánea del capitalismo; la agroindustria, que pretende convertir las planicies gauchas -que una vez fueron montes y ríos indígenas- en campos sembrados de soya es el último eslabón de una cadena que nace en la Conquista de América y se extiende hasta nuestros días.

La estela de destrucción que conlleva el ímpetu de la modernidad, y las avanzadas de un progreso que se construye sobre los restos de lugares y seres potencialmente destruibles, dejan una huella que puede rastrearse en la devastación de cuerpos y geografías. Se trata de "paisajes de conquista: una forma de uso, ocupación, explotación y saqueo del territorio que se convierte en ruinización del paisaje, lo cual es hoy la "marca" de [...] una espacialización particular del imperialismo", explica Mario Rufer aludiendo a la propuesta de Ann Stoler (Rufer, 2018, p. 116). La caña de azúcar, si atendemos a Michael Taussig, secó el valle del río 
Cauca tanto como a los habitantes negros que veían sus cuerpos consumirse en el trabajo extenuante de la agroindustria cañera, descrita por los campesinos con los que conversó "como una planta que lo seca a uno o se lo come" (Taussig, 1980, p. 129).

La mezquindad, dicen algunos barreños, suscita la furia del océano. A pesar de que la reconstrucción constante del pueblo ha estrechado los vínculos comunitarios y la gente se ha juntado para hacerle frente a la marea, la añoranza del tiempo en que la comida abundaba porque el mar entregaba y la gente trabajaba se acentúa en medio de la escasez y de la brusca alteración de la vida. Mares arrasados por barcos foráneos, envenenados con los restos de progresos ajenos y cundidos de muerte son el horizonte en que el mundo parece mezquino y menos exuberante que antes. En Aldana, Nariño, Laura Guzmán y Natalia Martínez (2019) han conversado sobre el tiempo de antes que, como en La Barra, es recordado con nostalgia por los campesinos. Según este acercamiento a aquellas montañas del sur de Colombia, antes de que el dinero irrumpiera en las relaciones solidarias, los potreros ocuparan el lugar del monte y los funegantes envenenaran el campo, el alimento, el agua y el trabajo abundaban. Hoy la mezquindad entre vecinos y el trabajo explotado y explotador de la tierra la han secado (como seca el azogue) y enflaquecido.

En las playas de La Barra, así como parece suceder en los Andes argentinos y colombianos y en los valles interandinos del suroccidente de Colombia, el colapso del mundo, experimentado mediante la violenta irrupción de una forma de producir la vida que destruye los lugares y las gentes de los que extrae la riqueza, se proyecta en "la angustia que aparece frente a una pesadilla política e histórica [y] es también el lamento de la muerte de una clase campesina que está por ser arrollada por la ola del 'progreso"' (Taussig, 1980, p. 165).

\section{Obstinados florecimientos}

Y, sin embargo, la vida en La Barra sigue descubriendo caminos, empecinada, caprichosamente. La destrucción es una posible invitación a la creación de lo nuevo. Pueden gestarse formas de solidaridad y cooperación que abran sendas de transformación y renacimiento (Gordillo, 2014, p. 264). En La Barra, la destrucción del pueblo ha fortalecido los lazos de la comunidad. El trabajo colectivo para reconstruir el caserío o para recoger los restos que el mar deja cuando se acerca, además del afianzamiento del consejo comunitario, así lo revelan. En los últimos años la gente se ha organizado en torno a la propuesta de un turismo comunitario que les permita sortear la llegada de foráneos sin depender de intermediarios. 
A pesar de que esta actividad económica incita en algunos casos el abandono de otras, como la agricultura de subsistencia que se articula con la producción pesquera artesanal para hacer frente a las dificultades que trae la presencia de grandes barcos camaroneros, la atención al turismo se ha hecho a partir de principios de reciprocidad entre quienes prestan ese servicio. Por ejemplo, hay una constante rotación de quienes se benefician al ofrecer hospedaje y alimentación con el propósito de que a todos y todas les corresponda de vez en cuando hacerlo.

La destrucción puede ser creadora. El mar corta, cría y le da vuelta a la playa. La huella del océano se inscribe en la arena y algunos le llaman corte y otros le llaman "versos"4: son los surcos con que ara y dice la existencia. Manos pescadoras hacen el mundo en tanto amasan la misma sustancia de que están hechas y son forjadas en el encuentro productivo que esculpe cuerpos humanos y otros no humanos que con aquéllos conversan. En los Andes colombianos, vuelta es un principio asociado a la regeneración de la vida y a una fuerza reproductiva que siendo brava amansa la tierra, y que es tan generosa como destructiva (Guzmán y Martínez, 2019). En el horizonte que dibujan las altiplanicies andinas al noroeste de Argentina, Alejandro Haber (2017) participa en una teoría local y concreta de la relacionalidad en la que se enredan cerros, humanos y antiguos a través de una crianza de la vida mediante la cual se destruye para crear y se crea para destruir. Luis Alberto Suárez (en prensa) ha hallado también en los Andes colombianos teorías que entienden que el derrumbamiento del mundo posibilita su florecimiento: los restos de un mundo que "da botes" son la semilla de fértiles crecimientos.

Me contó José Luis Grosso, en alguna sesión del seminario que dictó en febrero de 2019 en el doctorado de antropología de la Universidad del Cauca, que le contaron a él que en Portugal, a orillas del Atlántico, el mar dibuja líneas que la gente llama versos. 


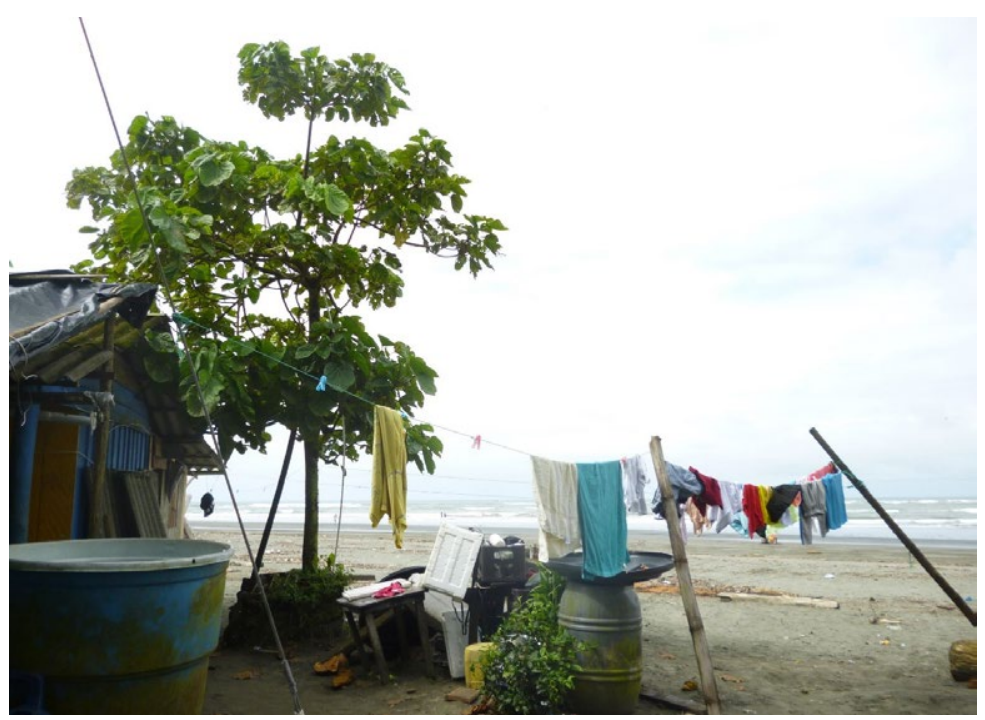

Imagen 4. La Barra, diciembre de 2019.

Fuente: archivo personal de la autora.

La presente reflexión ha querido pensar en esa forma de colapsar y florecer juntas en mundos como La Barra. El Pacífico colombiano experimenta una inestabilidad propia de sus rasgos biofísicos, al tiempo que enfrenta las sacudidas que la guerra y algunos ímpetus económicos atizan. La incertidumbre es constitutiva del horizonte litoral y sus habitantes han aprendido, en relación íntima con sus mundos de agua, a lidiarla y hacerla creativa. A propósito de cómo el maremoto de 1979 erosionó los suelos de la costa nariñense obligando a sus pobladores a cambiar de actividad económica, Jaime Arocha (1991) exalta "esa inventiva sociocultural ágil [que] se agigantó frente a las condiciones de cambio continuo del litoral Pacífico" (p. 104). La pérdida de los cultivos ante la esterilidad causada por la salinización que trajo el mar devino posibilidad de rehacer la vida mediante la pesca de jaiba en la ensenada de Tumaco. En las orillas fluviales del Atrato, la contundente evidencia de cauces trastocados y de vidas humanas y más que humanas deshechas por la arremetida minera de gran escala ha impulsado la apertura de una nueva "imaginación ecopolítica" que busca tejer los hilos rotos. Esto "supone sanar el río, recomponiendo los vínculos que lo amarran a las comunidades que moran en sus orillas" (Cagüeñas et al., 2020, p. 185).

Pretendo que las inquietudes y reflexiones que mediante estas letras pudieran intuirse se abracen a las urgencias de quienes tropelean con la marea y resisten sin claudicar en una playa -su playa- apretada por distintas y terribles fuerzas. Declaro situarme en el lugar en el que la gente con que converso defiende el suyo: contra la avanzada violenta 
del progreso y el desarrollo que vuelve balnearios las costas en que otros habitan y caminan la vida, que convierte los montes en aserríos y los mares en yacimientos de peces cuya existencia se diluye en mercancía; contra la avanzada violenta de una singular forma de vivir que se muestra universal y necesaria en tanto legitima la destrucción de otros tiempos y espacios pautados por la luna y mojados por la marea; contra la conquista interminable de la indómita selva que embruja y pierde en sus dominios a quien cree dominarla.

\section{Epílogo}

La inestabilidad por la que hace años me pregunto parece ser hoy la sustancia de nuestro tiempo. En el último año, la pandemia causada por la covid-19 ha puesto a temblar muchas certezas 5 . El mundo que conocíamos parece diluirse en una bruma espesa y se suceden días feroces en que en las calles la gente responde a las urgencias del hambre, mientras otros pocos resguardan sus refugios privilegiados ante el inminente contagio (así vi el mundo en Cali, Colombia, en los primeros meses de la cuarentena y el "aislamiento social obligatorio"). El terror de tocarnos y hasta de mirarnos es astutamente canalizado por las fuerzas del mercado: el deseo represado en el encierro se tramita groseramente: control, consumo (de quienes pueden) y miedo (hacia quienes no), máscaras que nos distancian y partículas peligrosas e invisibles que están en todos lados.

Lo provisional se muestra contundente en medio de esta vulnerabilidad permanente. Muerte, fugacidad, materia del tiempo: ¿por qué es tan desgarrador entenderlo?, ¿cómo confiar en que este estremecimiento abra grietas y hiera?, ¿cómo hacer que de la herida brote otra vida? Habrá que devolverle al ser humano su humilde lugar en una historia que le antecede y rebasa, y desmentir su privilegiada conquista de aquello que hoy se rebela erosionando las orillas de la tierra y desmoronando las humanas certezas. ¿Cómo imaginar otros sentidos y otras formas de vivir en medio de una crisis en que destellan tantas oscuridades como fulmíneos deslumbramientos? Desde las orillas nos enseñan: en La Barra la gente ha vuelto a sembrar lo que antes compraba porque el dinero del turismo ya no llega, y quizás las ballenas que se acercan a los abismos submarinos de Málaga celebran la momentánea ausencia de lanchas dementes y nadan con sus crías recién paridas en el profundo silencio del océano.

Para profundizar en reflexiones que la pandemia ha suscitado en esta parte del mundo, ver Quijano y Corredor (2020). 


\section{Referencias bibliográficas}

Anzola, J. (2017). Uno hace la finca y la finca lo hace a uno: Trabajo, conocimiento y organización campesina en Sucre, Cauca (Tesis de pregrado sin publicar). Pontificia Universidad Javeriana, Bogotá, Colombia.

Arocha, J. (1991). La ensenada de Tumaco: invisibilidad, incertidumbre e innovación. En América negra. $\mathrm{N}^{01}$ (pp. 87-113). Pontificia Universidad Javeriana.

Arocha, J. (1999). Ombligados de Ananse. Hilos ancestrales y modernos en el Pacífico colombiano. CES - Universidad Nacional de Colombia.

Arocha, J. (2004). Procesos de guerra y paz en el litoral Pacífico, en Dimensiones territoriales de la guerra y la paz (pp. 631-640). Universidad Nacional de Colombia.

Cagüeñas, D., Galindo Orrego, M. I. y Rasmussen, S. (2020). El Atrato y sus guardianes: imaginación ecopolítica para hilar nuevos derechos. Revista Colombiana de Antropología, 56(2), 169-196. https://doi.org/10.22380/2539472X.638

Chakrabarty, D. (2009). Clima e historia. Cuatro tesis. Pasajes: Revista de pensamiento contemporáneo, (31), 51-69. http://hdl.handle.net/10550/46310

Escobar, A. y Pedrosa A. (1996). Pacífico ¿Desarrollo o diversidad? Estado, capital, y movimientos sociales en el Pacífico colombiano. CEREC.

Escobar, A. (2004). Desplazamientos, desarrollo y modernidad en el Pacífico colombiano. En E. Restrepo y A. Rojas (eds.), Conflicto e invisibilidad. Retos en los estudios de la gente negra en Colombia (pp. 53-72). Editorial Universidad del Cauca.

Fals Borda, O. (1979), Historia doble de la Costa: Tomo 1, Mompox y Loba. Carlos Valencia editores.

Galindo Orrego, M. I. (2019). Viviendo con el mar: inestabilidad litoral y territorios en movimiento en La Barra, Pacífico colombiano. Revista Colombiana de Antropología, 55(1), 29-57. https://doi.org/10.22380/2539472X.569

Galindo, M. I. (en prensa). El mar se lleva la playa que trajo: huellas de un mundo inundado. En C. Gnecco y M. Rufer (eds.), El tiempo de las ruinas.

Giraldo Herrera, C. (2009). Ecos en el arrullo del mar. Las artes de la marinería en el pacífico colombiano y su mímesis en la música y el baile. Ediciones Uniandes.

Gordillo, G. (2014). Rubble: The Afterlife of Destruction. Duke University Press.

Guzmán, L y Martínez, N. (2019). Entrar y salir de la tierra. Un evento de la fuerza reproductora en el suroccidente andino colombiano. En L. A. Suárez Guava (ed.), Cosas vivas. Antropología de objetos, sustancias y potencias (pp. 207-245). Pontificia Universidad Javeriana.

Haber, A. (2017). Al otro lado del vestigio. Políticas del conocimiento y arqueología indisciplinada. Universidad del Cauca.

Haraway, D. (2015). Anthropocene, Capitalocene, Plantationocene, Chthulucene: Making Kin. Environmental Humanities, 6, 159-165.

Leal, C. (2000). Manglares y economía extractiva. En F. Correa (ed.), Geografía Humana de Colombia. Los afrocolombianos, tomo 6 (pp. 318-344). Instituto Colombiano de Cultura Hispánica. 
Leyva, P. (2003). Vulnerabilidad de la zona costera colombiana ante el cambio climático: Aspectos generales del cambio climático. El efecto invernadero. En N. Castillo y D. Alvis (eds.). El mundo marino de Colombia: Investigación y desarrollo de territorios olvidados (pp. 138-154). Universidad Nacional de Colombia, Red de estudios del mundo marino.

Marx, K. ([1844] 1985). Manuscritos: Economía y Filosofía. Alianza.

Molano, A. (2017). De río en río. Vistazo a los territorios negros en Colombia. Alfaguara.

Oslender, U. (2008). Comunidades negras y espacio en el Pacífico colombiano. Hacia un giro geográfico en el estudio de los movimientos sociales. Universidad Colegio Mayor de Cundinamarca, ICANH, Universidad del Cauca.

Quiceno, N. (2016). Vivir sabroso. Luchas y movimientos afroatrateños en Bojayá, Chocó, Colombia. Editorial Universidad del Rosario.

Quijano, O. y Corredor, C. (Comps.). (2020). Pandemia al Sur. Prometeo.

Rufer, M. (2018). La raza como efecto estructural de conquista: una hipótesis de trabajo. En R. Parrini, Y. Arce y E. Alcántara (coords), lo complejo y lo transparente. Subjetividades, diferencias, exclusiones. Lecturas latinoamericanas (pp. 101-128). UAM.

Ruiz-Serna, D. (2020). Ecúmene de vivos y muertos: mala muerte y reparaciones territoriales en el Bajo Atrato. Revista Colombiana de Antropología, 56(2), 21-50. https://doi.org/ 10.22380/2539472X.639

Segato, R. (2013). La crítica de la colonialidad en ocho ensayos y una antropología por demanda. Prometeo Libros.

Suárez Guava, L. (en prensa). Las ruinas no vistas o los restos de un mundo creciente. Derrumbes, huecos y palacios subterráneos en los Andes. colombianos. En C. Gnecco y M. Rufer (eds.), El tiempo de las ruinas.

Taussig, M. (1980). El diablo y el fetichismo de la mercancía en Sudamérica. Nueva Imagen.

Taussig, M. (2013). Mi museo de la cocaína. Universidad del Cauca.

Vanín, A. (2017). Las culturas fluviales del encantamiento. Editorial Universidad del Cauca.

Verdad Abierta. (19 de junio de 2012). Los orígenes de la masacre de El Naya. Verdad Abierta. https://verdadabierta.com/los-origenes-de-la-masacre-de-el-naya/

West, R. ([1957] 2000). Las tierras bajas del Pacífico colombiano. ICANH. 